\title{
LETTERS
}

Send your letters to the editor, British Dental Journal, 64 Wimpole Street, London W1G 8YS or by email to bdj@bda.org

Priority will be given to letters less than 500 words long. Letters should be typed. Authors must sign the letter, which may be edited for reasons of space

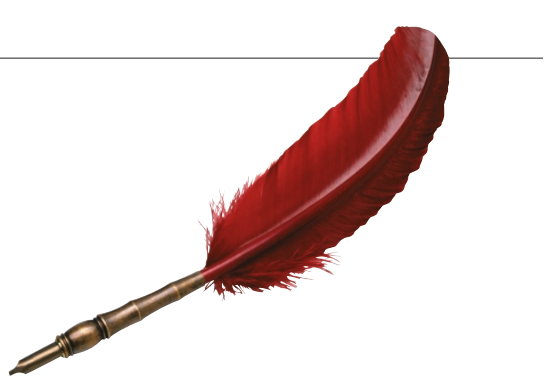

\section{Innocent patients?}

Sir, in reply to S. Mynard's comment in identifying the legal loophole, (BDJ 2004, 196:248) I do agree that the GDC should facilitate the formation of a compulsory statutory insurance mechanism for all practicing dentists.

This should be done by the GDC itself as suggested by S. Mynard through mandatory premiums into a fund and not by the dentists having to seek private medical insurance themselves.

What I do not agree with is the issue of 'innocent patients' suffering. I work in a fully NHS practice where over $70 \%$ of my patients are exempt from treatment charges and are eligible for free legal aid.

There is always a threat of legal action from them, which makes it difficult to function as a dentist. I have been stung once by an unmeritorious claim, where the insurance company settled for reasons of practicality and efficacy.

I am an extremely conscientious dentist and do my work with care and attention. I am also on the verge of completing my LLB and I understand what is and what is not a rightful claim.

However, there are negligence solicitors who exploit the large window of opportunity against dentists like me for their personal unjust enrichment by a series of threatening letters to the insurance companies knowing that there is a good chance of settlement.

I feel that the current legal protection for patients is a charter for relentless insurance claims that have no valid justification. Because of my experience there will be a lot of 'innocent patients' that I will avoid treating, and who will consequently suffer.

The target for remedy should not be the 'innocent patients' but the 'innocent society' and a statutory policy must be implemented with such a utilitarian goal in mind.

This is not to say that valid negligence claims must be swept aside since genuine claims require genuine advocates. If insurance is to be made mandatory, there should be a parallel statutory implementation for stricter regulation of the conduct of solicitors so that they will be accountable for sham claims. If this problem is not checked, the NHS crisis will become a NHS apocalypse.

M. Susdon

By email

doi: $10.1038 /$ sj.bdj.4811604

\section{The clinical coalface}

Sir, I was interested to read the article about CPD courses (BDJ 2004, 196:773$77)$ and their relatively weak impact on the practice of the dentists studied. The authors' suggestions for enhancing the value of courses were sensible.

However, in over 16 years of public sector employment and developmental training, the experiences from which I learnt most were not of the formalcourse-type.

As a newcomer to the field of nutrition for example, I spent four incredibly valuable days jobshadowing two community dieticians. I was left with a deep respect for their work - and an understanding of life at the clinical coalface that I could not have obtained any other way.

Mentoring too I found worthwhile both as a mentor to two colleagues, and as a mentee (to an author of a recent $B D J$ article).

Finally, I can distinctly remember my training manager telling me that the person/s who benefit most from a course are those delivering the training!

Having had the opportunity to lecture and teach others, I can vouch for the educational value of having to appear authoritative on a subject in front of a critical audience.

It might be a positive move therefore if the full spectrum of learning opportunities, not just 'chalk and talk' lectures or indeed interactive seminars, were reflected in dentists' personal development plans.

\section{Stillman-Lowe}

Reading

doi: $10.1038 /$ sj.bdj.4811605 


\section{Destroying establishments}

Sir, we should mourn the loss of the three dental schools in the UK, which have been closed over the last two decades. At the time that the closures were advocated a number of reports and submissions strongly protested about the grounds for these decisions.

The lack of availability of dental care is currently the subject of debate in the media and professional press. This confirms what a number of groups and individuals predicted at the time of these closures, that as a result we would be at risk of educating and training too few new dentists for the UK. I am writing as a retired dentist who qualified at Edinburgh Dental School and who subsequently worked as a consultant/senior lecturer at the Royal Dental Hospital, Leicester Square and as head of department and Vice Dean of Dental Studies, reader and honorary consultant at University College London Dental School. Each of these three dental schools and hospitals which were subsequently closed had historic backgrounds and a reputation for serving the local community.

I have since in a professional capacity had the experience and privilege of meeting again with many of my former undergraduate students and participating in their postgraduate education and training or working with them in running training programmes for other colleagues. I can vouch for the quality of dentist that was produced from these establishments.

I have also served as dental tutor at UCH and have recently retired from the post of Dean of Postgraduate Dentistry at the London Deanery; I have thus experienced first hand the additional roles served by dental hospitals and schools. They participate in the provision of continuing professional development courses to colleagues in practice, they run training programmes for colleagues aspiring to hospital careers and careers in specialist practice and they undertake research in both clinical and theoretical dentistry. The technique laboratories in dental schools also provide postgraduate practical instruction in new techniques.

As a result of the closure of two of the dental schools in London there is now a shortage of academic centres to participate in training programmes, to act as a catalyst for postgraduate activity and to provide course leaders for postgraduate education in the scientific, theoretical and specialist aspects of clinical dentistry. It would seem appropriate at this time, when there is a perceived shortage of dental treatment capacity, to reassess the grounds for the implementation of these closures. The documentation advising these closures resulted at the time in very considerable protest, which highlighted the lack of scientific background in the documentation. It was observed that insufficient epidemiological, public health or educational research evidence had been submitted in the papers that proposed the need for a reduction in the numbers of dentists being educated in the UK. These warnings were not heeded.

The closure of a dental school and hospital is virtually an irreversible process. The traditions of the institution, the team of experienced clinical and academic teaching staff, the dedicated premises and equipment and the availability of patients for clinical teaching are lost irretrievably.

As a result of the decisions to instigate these closures a considerable number of patients are now being seriously inconvenienced, and the dental health of patients has potentially been jeopardised. The solutions being proposed to rectify these deficiencies represent compromise solutions. Overseas dentists have not been trained with the needs of the UK population in mind, and require equivalence of knowledge and skills to be demonstrated together with language test as appropriate.

The proposal to encourage retired dentists to return to practice is a temporary expedient. The decision to increase the number of students in our remaining dental schools will inevitably stretch resources, and may result in both stress to already over-committed clinical teachers and competition amongst the students for dental units / chairs for clinical experience. There will potentially be a dilution of the quality and quantity of clinical skills obtained by the future graduates. It is necessary that these past events are considered carefully, and that future decisions are based on more careful analysis of evidence to avoid destroying establishments or practices that have withstood the test of time.

\section{M. Waite}

Suffolk

doi: 10.1038/sj.bdj.4811606

\section{Needless extractions?}

Sir, recently I was asked to examine the children of a family new to my practice. Before I examined the four-year-old daughter, the mother told me that she (the daughter) had been born with her two lower centrals erupted and that these had been extracted in the local hospital at the insistence of (presumably) the paediatrician, much against the mother's wishes. Indeed the mother had been told that she would not be allowed home until this had been done! I explained to her that this had been totally unnecessary (the child was bottle fed, so there was no difficulty with feeding) and she was thankful to have an opinion which agreed with hers. I made it clear to her that I was horrified to learn that this was being done in the year 2000 .

Surely this barbaric and needless practice is no longer part of paediatric teaching in this country? Have any other practitioners come across it in the recent past? Perhaps those in the profession with influence in this area should ensure that it ceases. This attractive four-year-old girl has been left with two missing lower A's marring an otherwise perfect deciduous dentition, for no good reason and the mother has been left to explain this to health visitors and nursery staff, who assume that they were lost through caries. The mother was naturally relieved to learn that this will not result in the absence of her daughter's permanent lower centrals.

\section{J. Watt}

Coatbridge

doi: 10.1038/sj.bdj.4811607

\section{Clinical techniques}

Sir, I am writing to point out an error in the article Recording the Retruded Contact Position: a Review of Clinical Techniques in BDJ 2004, 196:395-402. On page 398, discussing the Myo-monitor, the author states, 'Proponents of the Myo-monitor suggest that the 'jaw-closer' muscles act simultaneously, via reflex contraction, to produce a reproducible retruded mandibular position.' This is a grossly inaccurate statement. As the President of Myotronics-Noromed, Inc, I will hereafter correctly describe the function and objective of the Myo-monitor's use.

The Myo-monitor is a muscle stimulator which induces involuntary contraction of the muscles controlled by the facial (VII) and masticatory (V) cranial nerves. Through the relaxation of these muscles the Myo-monitor is used to achieve a rest position from which a 'neuromuscular occlusion position' is established. The article incorrectly asserts that the Myomonitor produces a 'retruded mandibular position'. According to Cooper ${ }^{1}$ 'Identification of the mandibular rest position is used as a reference point for the selection of a neuromuscularly based occlusal position. Physiologic ergonomic principles dictate that the muscles function best at resting length.' 'From the rest position, the TENS stimulation is increased slightly, causing the mandible to rise on a trajectory:' 'A therapeutic occlusal position is selected approximately $1 \mathrm{~mm}$ above the rest position on the neuromuscularly 
stimulated trajectory. When used as described, the Myo-monitor most commonly produces a, physiologically valid mandibular position, most certainly not in a retruded position as stated in the article by Wilson and Banerjee.

\section{F. Adib}

USA

1. Cooper B C. The role of bioelectronic instrumentation in the documentation and management of temporomandibular disorders. Oral Surg. Oral Med. Oral Pathol 1997: 83: 91-100.

\section{The authors of the paper respond: We} thank Mr Adib and wish to respond to the comments regarding our 'grossly inaccurate statement.' In our summary of the Myo-monitor, we state that the Myomonitor is a jaw muscle stimulator which is :.reputed to achieve muscle relaxation and produce a neuromuscular mandibular position'. This correlates with your explanation. Thereafter, increased transcutaneous electrical stimulation of the mandibular elevator muscles, via cranial nerves V and VII, will produce mandibular closure about an arbitrary condylar axis ${ }^{1}$, or trajectory as you put it.

This is not the retruded axis in the purist sense, when related to the Glossary of Prosthodontic Terms ${ }^{2}$, but it does produce mandibular closure, and ultimately tooth contact, on a path posterior to that of the subject's Intercuspal Position (ICP) ${ }^{1}$. This must mean that the mandibular position produced by the Myo-monitor is a retruded one relative to ICP, and thus our statement 'Proponents of the Myo-monitor suggest that the 'jaw-closer' muscles act simultaneously, via reflex contraction, to produce a reproducible retruded mandibular position' is entirely valid.
Whether this retruded mandibular relationship is indeed reproducible was considered in our appraisal of the available literature. doi: 10.1038/sj.bdj.4811608

1. Noble W H. Anteroposterior position of 'Myomonitor' centric. J Prosthet Dent 1975; 33: 398-401. 2. The Academy of Prosthodontics. Glossary of Prosthodontic Terms. J Prosthet Dent 1999; 81: 48106.

\section{Student debt}

Sir, in response to the letter suggesting that student debt deters people from entering postgraduate education $(B D J$ 2004, 196:661) I would suggest that the author may not be sufficiently keen on specialising. Yes, debt may well be a deterrent but it is a case of making sacrifices in other areas to pursue your career goals. It is perfectly feasible to exist on an SHO wage and pay off debts accrued as a student. You just need to stick to a budget. You may not be able to purchase everything you want or live the lifestyle you wish whilst studying but this has been the situation for years.

At times it can be frustrating when your GDP peers have nicer houses and cars etc. Rather than blaming the BDA for a lack of action I would suggest that students are educated about debt and given more advice about how to manage their finances. Making them listen may be more difficult. I qualified in 1997 with $£ 15,000$ of debt (I didn't listen to any advice). I am about to finish a 3 year postgraduate training programme with even more (new) debt. Has it been worth it? Absolutely. I wouldn't change a moment of it.

\section{J. E. Cooper}

By email

doi: 10.1038/sj.bdj.4811609

\section{Pride in a profession}

Sir, as one of the thousand or so members of the BDA unceremoniously pushed out of the profession by the huge increases in the Annual Retention Fee (ARF) for this year I would like to point out one factor that I have not seen mentioned in any of the correspondence.

Retirement brings not only a great reduction in income but also a loss of the ability to claim tax relief for the ARF. This means that whereas a practising member pays only a percentage (depending on his top tax rate) of the nominal fee, the retired dentist has to pay the full whack!

Mr Mathewson is of course correct when he argues that the fee buys a license to practise, the inference being that the license is irrelevant once we hang up our handpieces and scalpels for the last time. But that is not the only consideration for those of us who are affected. We have spent forty years or more working for something rather more than just earning a living - an intangible item perhaps, but real for all that. It is pride in a profession which strives to benefit society at large, and our interest continues after retirement.

Mr Mathewson's other argument is not, in my view, valid. He says that a reduction in the fee for any group is unfair on those paying the full fee; but all dentists would be able to benefit from a reduction when they reach retirement, so there is no unfairness. I do not claim that we bear much resemblance to a shorn lamb, but a little tempering of the wind would be much appreciated!

J. G. Owen

East Grinstead

doi: 10.1038/sj.bdj.4811610 